\title{
Ontario's Revised French as a Second Language Curricula: Reflections on Culture Teaching and Oral Proficiency Development in Core French
}

\author{
Rochelle Gour \\ University of Calgary, Calgary, Alberta, Canada
}

\begin{abstract}
Ontario's Ministry of Education has recently redesigned two French as a second language (FSL) curricula in the elementary [1] and secondary [2] teaching panels. This curriculum shift requires a thorough and ongoing investigation to determine how teachers perceive Ministry modifications and how they plan to implement such changes in daily practice. This paper summarizes initial curriculum reactions and implementation strategies of the 2013 [1] and 2014 [2] Ontario FSL curricula through a Master's thesis [3] and personal practitioner-teaching experiences with the Core French Program. It also outlines an overview of future doctoral-level research that will build on the previous elementary-level research project [3].

Curriculum, culture, and interculture as concepts are defined through a specific vantage point as a newly-licensed FSL non-native French teacher. This article presents a brief overview of Ontario FSL education, reflecting the curriculum revision process. As a returning Ontario FSL secondary school teacher, curriculum change is then described and reflected upon with a personal researcher-practitioner stance through a metaphorical conceptual framework of a French salad.

Initial conclusions establish that the Ontario FSL curriculum revision process is overall positive for student acquisition of French language and cultures, but that teachers may require ongoing practitioner

whereby its users, otherwise known as teachers, personalize programming expectations into their unique classroom discourses.

Within the Ontario FSL context, curriculum truly reflects this currere [4] standpoint as the teaching of French is a dynamic process, containing distinct classroom realities and encompassing both affordances and constraints for the curriculum user.

Curriculum revisions established by powerful stakeholders such as the Ministry of Education, can be cause for teacher-anxiety. This is particularly the case for newly licensed teachers who seek to become curriculum 'gurus,' yet who lack an extensive teaching base. Non-native second-language teachers may also feel incompetent or unprepared to teach culturally-relevant language content to students with a currere [4] perspective to curriculum.

From personal experience as a newly-licensed and non-native Ontario FSL high school teacher, curriculum success is established when an educator addresses all the macro and micro expectations. At the other end of the spectrum, some teachers completely disregard a curriculum document, letting it collect dust in their workroom shelves, deeming it to be irrelevant and incompatible with their day-to-day classroom realities. Therefore, living the currere [4] experience, can be considered as a double-edged sword for curriculum success, imposing challenges to certain teacher-types.
\end{abstract} development to effectively implement the new curricula.

Suggested future research seeks to explore how the various definitions of this article are lived in the unique Ontario FSL community, as well as how the revised curricula [1-2] continue to be implemented in daily practice by the curriculum user.

\section{Defining Curriculum Success}

It is important for stakeholders in education to think about how curriculum is defined, implemented, and influenced in modern society. Reconceptualists perceive curriculum as a multilayered entity, riddled with discourses that are influenced by current time and by influential stakeholders. Curriculum, therefore, is a lived experience, or currere [4]

\section{An Overview of Ontario FSL Programs}

Ontario has recently published two curricula for the elementary [1] and for the secondary teaching panels [2]. It has been approximately 15 years since the previous curriculum revisions. Ontario FSL teachers are currently implementing this mandated curriculum change which has implications affecting their unique instructional practices. As such, their individual curriculum 'road map' is still being defined and adapted.

While the focus of this article is on the Core French (CF) high school context, a brief description of each program is described to contextualize the Ontario FSL 'landscape'. In Ontario, students wishing to pursue French as a second language have three options: Core 
French $(\mathrm{CF})$, Extended French (EF) or French Immersion (FI). As there are no definitions to distinguish the various programs, $\mathrm{CF}$ is defined as 'essential' French for basic communication whereas, the Extended (EF) and French Immersion (FI) programs extend to cross-curricular activities such as teaching science in this target language (TL). Irrespective of the French program, according to the Ministry of Education [2], all Ontario FSL students need to "communicate effectively, and thrive in an ever-changing global community" (p. 3). The Ministry expects therefore, that teachers offer multiple opportunities for interaction at the international level.

Each Ontario FSL program establishes various requirements for successful completion of the elementary school program. For example, the elementary curriculum [1] has stated that CF students must complete "a minimum of 600 hours" (p. 15). Extended French and French Immersion students must exceed CF hours with EF requiring students to complete "a minimum of 1260 hours" (p. 15) and FI students to complete "a minimum of 3800 hours" (p. 16) by their final year of elementary school.

Specific to the Ontario FSL high school context, students have the option to pursue French in either the academic or applied stream. In the revised secondary curriculum [2], students must complete, "One FSL credit (110 hours) from any of the three programs" ( $p$. 16) for graduation. From personal experience as a current high school FSL teacher, academic French aims to teach students complex language structures whereas applied and open-level classrooms focus on the basic working knowledge of French.

\subsection{The Newly-Added Intercultural Sub- strand}

Language and culture are not distinct entities but rather, metaphorically speaking, identical twins. Both the elementary [1] and secondary [2] FSL curricula have included intercultural education as an official sub-strand that must be taught in all FSL programs and in all four curriculum strands which are listening, speaking, reading and writing. For example, the Grade $9 \mathrm{CF}$ applied-level listening strand of the curriculum, [2] has required that students, "demonstrate an understanding of information in oral French texts about aspects of culture in diverse French-speaking communities and other communities around the world, and of French sociolinguistic conventions used in a variety of situations and communities" (p. 74). Therefore, the Grade $9 \mathrm{CF}$ applied-level teacher must include multiple French cultures into their programming while extending culture-teaching to other non-French communities.

Additionally, while offering students various listening activities, Ontario FSL educators also need to expose students to sociolinguistic conventions such as "variations in pronunciation and dialect" (p. 76) in the Grade $9 \mathrm{CF}$ applied-level program of the high school curriculum [2].

The newly-added intercultural sub-strand initiates change for enhanced cultural opportunities in the Ontario CF teaching-context; however, this curriculum addition must be critically analyzed for its feasibility in the beginner-level FSL classroom.

2.1.1. Problematizing Culture and Interculture. The newly-added curriculum sub-strand of intercultural education is a dynamic addition that sparks reflection as to how concepts of 'culture' and 'interculture' are defined, characterized, and operationalized in the Ontario FSL CF context for introductory learners of French.

To some stakeholders, culture is statically defined [5]. For example, certain individuals may consider a key cultural element of all France citizens as lovers of baguettes. Personal experience has noted that previous teaching of French in Ontario merely focused on specific regions of France and Quebec; notably Paris for France, and Montreal and Quebec City, for Quebec. This pedagogical choice lost the opportunity to explore other regions where French is spoken. Language teachers who view culture as a fixed entity, may also take comfort in reusing resources that no longer represent the current societal trends. As a result, students learning in this culturallystatic classroom may leave the program stereotyping all native speakers with certain characteristics, loosing opportunities for other perspectives of French culture.

Contrary views however, view culture as dynamically rooted through the consideration of multiple lived realities [5]. In fact, with this perspective to culture, even monolingual individuals live out multiple cultures in their daily lives. For example, one can consider the characteristics of school versus home culture whereby the individual modifies his or her personality in accordance with the unique discourse and the distinct community members of each space.

The Ontario Ministry of Education [2] has suggested that culture includes concepts such as "personal, cultural, and universal behaviours, traditions, and beliefs" (p. 10). More specifically, the curriculum's glossary has expressed that culture contains, "The customary beliefs, values, social forms, and material traits of an ethnic, religious, or social group. It includes the arts, literature, lifestyles, and traditions" (p. 380) in its characteristics. This could mean for example, that students can learn how to introduce themselves to a classroom colleague which would differentiate for exchanges with a potential employer.

Jenkins and Purushotma [6] have also argued for culture-teaching that contains "low barriers [and a] strong support [with] some type of informal 
mentorship" (xi). Reflecting on their stance, there is an importance for unique teacher-training of language teachers merely presenting cultural input, to providing student with adequate learning-time to explore, extend, train, and critically think about introduced content.

Can culture even be classified and fragmented? Furstenberg [7] has also thought of this encapsulation tendency that language-teachers often face in their classrooms. From personal teaching experience, culture is 'packaged' into portable booklets, posters, and films so that it can be easily 'transported' from classroom to classroom and from floor to floor in the high school setting where a homeroom is often lacking for $\mathrm{CF}$ teachers.

In the beginner-level second-language classroom, personal experience and that of colleagues, also consider the priority of teaching to their unique learners. A key question remains how to balance culture-teaching with language proficiency for students who are still learning how to state their home address in the target language. For example, when exposing these students to authentic films, subtitles are also problematized. Should they be in the students' mother tongue, or completely abolished from the learning experience? It forces the educator to select one purpose for cultural activities in this classroom: the goal to comprehend a film, or the objective to merely hear authentic French in context.

Additional reflection analyzes the meaning of 'authentic' If culture is dynamically-defined and an ever-changing concept, reflections need to be made whether stakeholders can truly label culture as 'authentic'. For example, a common Quebecois tradition, is to collect maple syrup during the winter months with friends and family for a 'true' cultural experience. This 'authentic' learning opportunity does reflect typical common culture of this region; however, the art of maple syrup collecting may not be unique to Quebecois culture. Arguments can be made suggesting that maple syrup collecting is more of a traditional event rather than a unique, authentic opportunity solely relative to the Quebecois culture.

Ironically, in the Ontario FSL high school curriculum [2], 'authentic' is the dominant adjective that describes culture and is expressed in the following examples such as, "authentic purposes" (p. 8), "Authentic oral communication" (p. 9), "authentic way" (p. 9), "authentic situations" (p. 9), "authentic and relevant contexts" (p. 10), "authentic materials" (p. 11), "authentic resources" (p. 15), "authentic purposes" (p. 23), "authentic tasks" (p. 35), and "authentic information" (p. 51).

While authentic is not formerly defined in this program [2], its glossary has clarified authentic language tasks which, "involves using language in relevant real-world situations (e.g., exchanging emails with a friend, making a purchase in a store, reading the menu from a restaurant, listening to a podcast on a subject of interest) to enhance one's understanding and/or one's ability to communicate" (p. 379). Further, authentic materials are considered to be, "originally created in French and intended for a general French-speaking audience (e.g., newspaper articles, short stories, novels, poems, television programs, films, websites). Language structures in authentic materials are not simplified or adapted, as they are in texts designed specifically for Frenchlanguage learners" (p. 379).

Initial interpreting this definition suggest that the Ontario Ministry of Education asks FSL high school teachers to preserve the cultural integrity of the source but provide students with ample exposure for eventual comprehension. This practice may impose challenges for $\mathrm{CF}$ teachers who struggle in maintaining student engagement with incomprehensible content as the learners 'shut down' when the language-learning is unapproachable.

In research, Furstenberg [7] has observed that online cultural exchange opportunities such as the Cultura classroom, allow its users to post their comments and overall experiences in their mother tongue to ensure, "equal opportunity for all students, on both sides, to fully articulate their thoughts and ideas" (p. 331). By providing students with this mother tongue option, do they lose opportunities for target-language fluency development? These personal examples and others, problematize the order of teaching the identical twins' of language and culture and the purpose of each activity that is presented to language-learners.

Additional questions regarding who is the cultural 'expert' - notably, the native or non-native teacherspeaker are also often considered by stakeholders. Furstenberg [7] has recognized previous societal norms for culture-teaching to be merely taught by "anthropologists" (p. 329) and not of languageteachers. This point may even challenge native teachers who's unique and lived monocultural experience may be inadequate in the international setting as they may not be official cultural researchers.

Byram, Gribkova and Starkey [8] have suggested that second-language teachers transition from merely transmitting culture through multiple input opportunities, to providing student-driven research inquiry of cultural content. They also have encouraged educators to assist students in understanding how cultures function in relation to one another and how societal perceptions are influential for the communication process amongst interlocutors.

The second-language teacher can benefit from the multitude of cultural opportunities via the Internet that offers students real-time access to lived experiences. It is also a mechanism for the language-learners' selfexpression to a larger online community of interested interlocutors. Furstenberg [7] has reminded teachers that the Internet, "has brought the outside world right into our students' homes and into our classrooms, providing students with direct and equal access to the 
complex, rich, and multifaceted world of the target culture" (p. 329). The author [7] has also recognized however, that this new teaching medium still resurrects "old questions" (p. 329) of cultureteaching. To clarify, language-teachers may still encounter problems of deciding what, who's culture to teach, and how to render it accessible, notably for the beginner-level language learner.

'Interculture,' as a concept, is also important for teachers to consider and clearly distinguish in the Ontario FSL environment. Elsen and St. John [5] have recognized the importance of inter in culture where the learner engages in a comparative analysis of the foreign culture with the individual's lived experience. Therefore, according to Elsen and St. John [5], a successful intercultural communicator should "comprehend the knowledge, affective and skills components needed to achieve communication goals [...] in intercultural contexts" (p. 27).

Specific to the Ontario FSL high school curriculum [2], interculture has mostly been referred to as "intercultural awareness" or "intercultural competence" (p. 10). According to the Ontario Ministry of Education [2], they have been identified as the top priorities of the revised program, otherwise known as, "essential elements" (p. 10). As evidenced in the high school program [2], FSL secondary school teachers must, "encourage students to develop their intercultural awareness by exploring diverse cultures and expanding their ability to differentiate between personal, cultural, and universal behaviours, traditions, and beliefs. In addition, educators should encourage students to develop the attitudes, knowledge, and skills, including their Frenchlanguage skills, needed to interact with people in French-speaking cultures effectively and respectfully" (p. 10).

To successfully offer both intercultural recognition and development opportunities for FSL students, there must be ample classroom opportunities for exchange whereby the learner shares his or her identity with a target language cultural expert. Exchange is also established when language-learners communicate their lived experiences to other students of the same classroom for a sense of a welcoming affinity space.

Intercultural education is not intracultural education to solely share one's lived experiences with another. Skutnabb-Kangas and McCarty [9] have recognized that visible and hidden cultural groups exist and that the language choice may "minoritise or distort some individuals, groups, phenomena, and relations while majoritising and glorifying others" ( $p$. 1).

Even with the positive shift from intra to intercultural consciousness, many researchers have critiqued the terminology as potentially racist constructs as interculture may not be adequately effective in extending one's cultural learning. In fact,
Witte [10] has recognized that interculture as a term, can be a catalyst for societal division. Witte [10] has suggested a shift from interculture to a transcultural viewpoint for a true "interplay of cultures" (p. 231) whereby the language learners "create instead their own original and creative lifestyle beyond the constraints of a culture" (p. 231). It is through this ongoing interplay, that learners break constrictive divisions of racism and cultural boundaries. Individuals with a transcultural approach to culture, often move from personal discourses and personas as they interact with the targeted interlocutor. In fact, a transcultural approach to language-learning recognizes the hybridity of culture in lieu of a static state. As a result, there is an ongoing need for secondlanguage teachers to engage in cultural sensitivity by not excluding 'other' or inferior cultural groups of the target language into the dominant cultural sphere.

However, a review of the Ontario FSL secondary curriculum [2] has observed that the word transcultural as a concept, does not appear in any of the curriculum language. This is a finding that may implicate the future of culture-teaching in the Ontario FSL programs. For example, future research can determine how FSL educators expose students to a multitude of French cultures such as through compartmentalized units in lieu of a fluid and pluralistic viewpoint to culture.

As the word is not formally inserted into this policy document, teachers need to review all curriculum expectations and other content to find transcultural teaching opportunities. For example, in the CF, Grade 9 applied program [2], a highlighted teacher prompt, asks the student to reflect upon their audio content of a francophone community to determine both similarities and differences of cultural traditions with their mother-tongue culture: "Qu'est-ce que tu as appris à propos de cette communauté francophone? En quoi est-ce que leurs traditions sont semblables aux tiennes?" (p. 76).

This teacher prompt found in the program [2], extends notions of interculture, to a pluralistic suggestion whereby the same student can also understand and respect cultural values in the prompt continuation: "En quoi sont-elles différentes?" "Comment comprends et respectes-tu les valeurs des autres cultures?" (p. 76). Unfortunately, this example is not a mandatory component of the curriculum. By it merely being a proposal for the classroom, its realisation may be short-lived by the curriculum user who is franticly prioritizing the implementation of 'official' curriculum expectations rather than the 'extra' teacher prompts.

An initial solution for pluralistic culture-teaching, suggests that teachers first understand the difference between 'French' and 'francophone'. The revised high school program [2] has not defined these two concepts. Often, French-culture and francophone culture are simultaneously used amongst 
stakeholders. Researchers such as Cooke [12] have extended non-francophone teachers of FSL classes to either English-dominant or French-dominant. For example, Cooke [12] identified that French-dominant Ontario CF teachers are not of French origin but "identify French as their most comfortable language" (p. 6) used in their FSL classroom. In this regard, 'French' speaks more to linguistic proficiency rather than cultural knowledge.

Francophone teachers are individuals who officially originate from a country or other region that allocates the French language as an official tongue. One could also argue, however, that being of francophone descent, does not automatically imply French-language or French cultural proficiency, especially if this individual immediately relocated to a non-francophone community or abandoned exposure to this language. These example reflections capture the dynamic nature of what is French and francophone for curriculum operationalization.

Regardless of the teacher's own language identity, students need to be exposed to ample opportunities to celebrate their own non-French cultures in the FSL classroom. Additionally, language-learners need opportunities for creative culture-making moments, or Witte's [10] "interplay" (p. 231) of the francophone world where students eventually come to discover more similarities of other groups than differences.

Language-teachers often question what constitutes as proficiency. Furstenberg [7] has extended this reflection specifically to the feasibility for proficiency in second-language classrooms that are subject to constraint time-slots. Additional reflections also consider how to adequately assess intercultural understanding, and notably, for the language-student beginning his or her journey in the target language.

In recent years, assessment is becoming dynamically defined. The previous classroom walls that previously confined language and culturelearning, have extended to third spaces such as the high school hallways, extracurricular opportunities, and within the student's bedroom become meaningmaking, pluralistic opportunities for culture. This shift for student-centered learning can problematize teacher assessment practices regarding equity and feasibility.

\section{Necessary Curriculum Reform for Ontario Core French Education}

While it is normal that Ontario's Ministry of Education annually completes curriculum reviews across disciplines, Ontario FSL CF elementary teachers [3] and personal teacher experience, view the curriculum revisions as true paradigm shifts [3], undergoing a reconstructive curriculum 'facelift'.

This paradigm shift was necessary due to Ontario's negative history with FSL education. For example,
Cummins [11] has observed that the poorly designed programs contributed to significant student drop-out rates. Others, such as Cooke [12], have identified teacher attrition out of FSL programs for non-French teaching roles.

In the past decade, the previous curriculum success was the ability to teach French with a focus on grammar. In fact, grammatical accuracy dominated the previous Ontario FSL curricula. This is believed to have discouraged students from pursuing ongoing French studies as it did not represent the day-to-day French exchanged by native speakers.

The Canadian Association of Language Teachers (CASLT) [13], has already identified that CF was the most frequently enrolled program in Ontario. Ironically, other FSL stakeholders including the House of Commons [14] and Cooke [12] have identified that this was a marginalized and abandoned FSL program.

Netten and Germain [15] noted that students were also discouraged to pursue French as a second language due to the lack of oral-language practice and authentic cultural exposure, notably, the 'real' French, in their classrooms.

From personal experience using the previous curricula versions, it was apparent that many FSL teachers lacked sufficient classroom resources to effectively teach the programs and offer culturallyrelevant experiences to students. Most often, French 'culture' was reserved for 'culture-Fridays' whereby teachers would initiate the weekend with Frenchlanguage films dubbed in English. These were days for teacher and student 'breaks' from the grammarheavy workweek and for teachers to 'checkoff' the previous cultural curriculum expectations.

This type of media activity lacked discussion time to extend culture-teaching moments with beginnerlevel French students. For example, many missed teaching opportunities could have asked students to research regions of the movies to determine if accurate representations of the portrayed cultural groups were present in the films. Discussions could have been initiated by the teacher to ask students to think about the instilled cultural values of characters and to identify common beliefs of the francophone films with the students' lived culture for a deeper connection to the movies.

Due to the example teaching experiences using the former curricula, the Ministry of Education's revisions to the Ontario FSL programming have truly shifted from a mere procedural revision process to a necessary 'facelift' for French-language revitalization. 


\section{The 'Newbie' Non-Native Curriculum Users}

The research inquiry of this article reflects an ontological stance, otherwise known as the researcher's lived reality as a newly licensed researcher-teacher. Additionally, by being a nonnative French teacher-speaker, curriculum operationalization may be implemented somewhat differently than a francophone FSL educator.

Personal experience as well as experience from fellow colleagues, 'live' the CF world as many of CF teachers were also previously $\mathrm{CF}$ students having been exposed to the previous curriculum iterations.

As the revised 2013 [1] and 2014 [2] FSL curricula are new in Ontario, many FSL teachers may lack the experiential teacher knowledge to effectively teach the new curricula. Stakeholders may question the expertise of non-native French speaker-teachers to effectively implement the curricula with a focus on culture and oral proficiency. The 'newbie' Ontario FSL CF teacher may also find the curriculum shift from grammatical accuracy to oral proficiency challenging without the abundance of technology in predominant English-language communities. Even with many Ontario FSL teachers having proficiency with the previous FSL high school curriculum, teacher development and change may be necessary to effectively deliver the new program [2].

Despite the richness of possibilities for social interaction in the second language classroom, it is important to consider potential classroom constraints for a profound intercultural exchange. Witte [10] has argued that the second language classroom does not reflect true immersion into the target culture to allow for student understanding of cultural "structures and norms [such as] skills, customs, folkways, institutions [and] beliefs" (p. 262). Jenkins and Purushotma [6] have also stressed the importance for real learning that may not occur in language classrooms that rely on "depersonalized" (p. 39) textbooks. Witte [10] has also identified that culture-learning may pose a threat to one's original culture for fear of language-learners "losing their identity and their selves in the third spaces" (p. 304). Due to the dynamic nature and potential difficulties of oral fluency development and intercultural education in the second language classroom, additional research is imperative to explore curriculum management in the Ontario FSL context.

\section{Engagement or Despondence with the Elementary FSL Curriculum}

A most recent Master's-level thesis [3] was an exploratory case study that investigated elementarylevel, CF teachers' perceptions and management strategies during the first year of official curriculum implementation in 2014. The middle-school context from grades four to eight was the focus of this study as it is the 'mid-point' of a student's career in the province. In the Ontario FSL context, this is a critical period for FSL learners as it is the midway of completing their mandatory French studies before Grade 9. Additionally, at the eighth grade, FSL students, parents and teachers, decide on which FSL program to enroll in for the student which could be either the academic, applied or open-level program. The stream choice often reflects the student's overall perception of the usefulness of French in their lives. From personal teaching experience, students often inform their Grade 9 FSL teachers that academic is for interested learners with applied and open-level streams for students who merely wish to complete the final FSL course requirement for eventual high school graduation.

The four teacher-participants of the study were all non-native French speaker-teachers working in the Greater Toronto Area (GTA) in the public and Catholic school systems. In terms of professional teaching experiences, there was a balanced level of newly-licensed FSL teachers along with seasoned practitioners working more than 15 years in the profession. They all described themselves to be 'ambitious' FSL teachers through their multiple Board-level and school-level professional development initiatives. From being a corrector of a national exam in France, to pursuing an international exchange to improve French proficiency-levels, each teacher-participant could be characterized as an 'exceptional' CF teacher.

Data was drawn from multiple sources to provide greater insight into practitioner experiences using the new elementary curriculum [1]. To begin, a questionnaire was distributed to each participant regarding initial curriculum perceptions and management strategies. Next, one-on-one interviews were conducted whereby each teacher shared personal classroom experiences evaluating and implementing the new curriculum. Finally, one focus group concluded the study where all four participants had the opportunity to intermingle and engage in a networking opportunity. For the focus group, each educator was asked to illustrate his or her curriculum 'identity' on chart paper which was eventually discussed in an open discussion amongst all participants as well as the researcher who recorded the conversation. Discussion topics included reasons for drawing particular illustrations, color-choices and elaborating on what was excluded in the drawings. The participants also discussed their overall growth implementing the new curriculum over the course of the study.

D'Artagnan was the only male participant and the oldest FSL teacher of the study who conceptualized himself as 'Moses' as illustrated in Figure 1. Moses was chosen because he felt that he was already an 
expert with FSL curricula due to his Ministry-level interactions and overall number of teaching years in the profession. Irrespective of his position, he too, felt uneasy with some of the curriculum revisions. According to the Master's study [3], D'Artagnan thought that the official intercultural strand required "special support" and appropriate "grade-level resources" (p. 52). He admitted that his planning style had to evolve with the new curriculum as he had to teach his students how to re-learn French class routines such as playing games. Previously, he noted that his students "were used to drill [...] and copying notes into their notebooks" (p. 52). Despite his positive attitude towards the revised elementary curriculum, D'Artagnan drew a cartoon bubble voice in the form of an administrative announcement. This represented his consistent pressures and interruptions from authority in his school building which prevented a fully successful curriculum implementation.

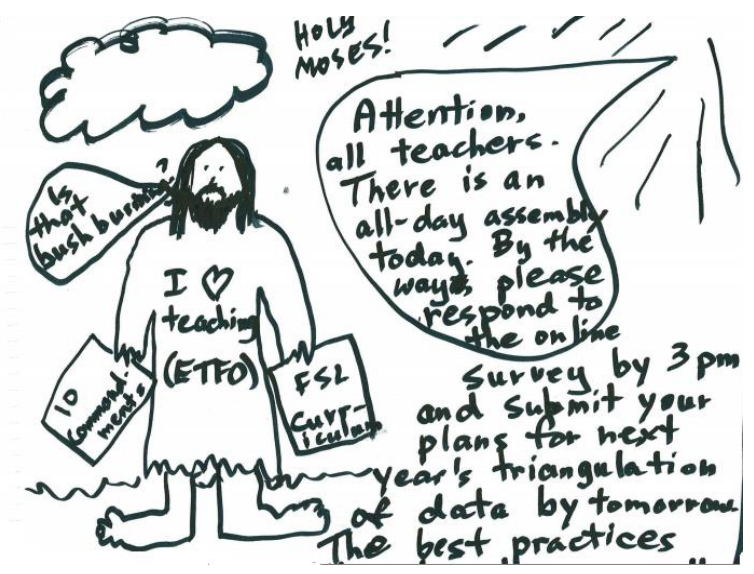

Figure 1. The expert FSL curriculum user

Isabel was the second experienced teacherparticipant of the study [3]. For example, she also had multiple FSL teaching opportunities, having taught since the early 1990s. Like D'Artagnan, Isabel engaged in extracurricular FSL leadership opportunities such as textbook writing and workshop facilitation for various teaching associations.

Despite her number of years inside and outside of the FSL classroom, Isabel continuously felt unprepared for the new curriculum, which was a striking finding. In a particular example identified in the thesis [3], Isabel felt that the previous elementary program was simpler to teach as the FSL educator was more of a passive "gardener" (p. 85) who was only required to provide students with the French 'seeds' and then observe them growing with their secondlanguage development. Additionally, Isabel found the older curriculum to be easier to implement due to "more rote-learning and more based on the vocabulary and phonics and pronunciation and surface things" (p. 85 ) as compared to the new curriculum where Isabel stated, “There's nothing!" (p. 85). In fact, Isabel expressed her overall frantic state as a new curriculum implementer of the 2013 program which is illustrated in Figure 2.

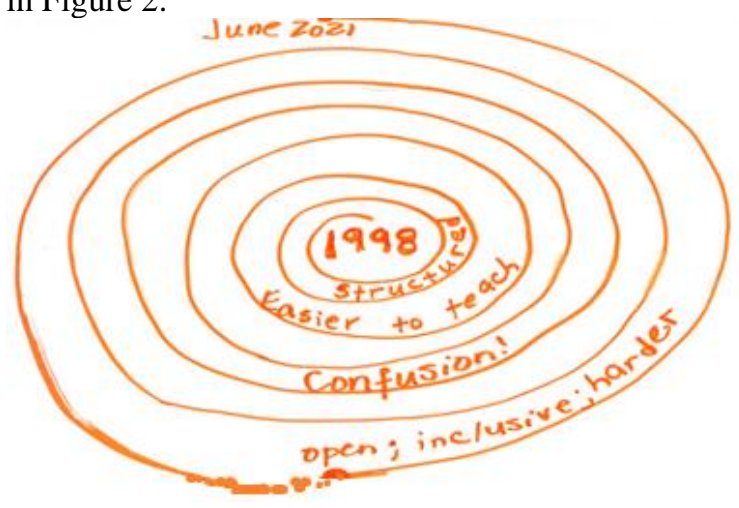

Figure 2. The 'dizzy' curriculum user

Part of her reasoning for this spiraled illustration was her belief that the new curriculum modeled firstlanguage acquisition which she felt to be unrealistic in the beginner-level classroom. This new learning reality required Isabel to reconsider pre-existing teaching resources and locate authentic, yet age and level-appropriate resources. This proved to be a serious challenge for Isabel. Even with her ambition to use resources such as YouTube and simplified online French magazines to her students, Isabel still felt that they did not support student interest or current learning ability with the target language. This experience also reflected her difficulty in addressing the metacognition sub-strand as the resources could not help her students simplify difficult authentic content to align with the beginner-level of French.

Even though she had an ethnic alliance to the West Indies, she did not consider herself to be a native speaker nor cultural expert. For example, Isabel admitted that she did not know "all the stories, all the history, all the current music" (p. 86), imperative for a rich intercultural experience.

Prior to launching this exploratory case study, it was assumed that the two newly-licensed FSL teachers (Madeleine and Helena) would both have a positive attitude regard to the revised elementary curriculum [1] because of their recent training during their teacher's college program. Their attitudes, however, were different: Madeleine maintained a more positive approach to curriculum change than her counterpart, Helena. Figure 3 summarizes Madeleine's curriculum operationalization beliefs and techniques in the form of a metaphorical puzzle.

Essentially, Madeleine was cautiously optimistic with regards to the curriculum implementation process. She thought of herself as a puzzle-builder, carefully selecting the most appropriate piece to form an accurate illustration of her CF classroom. As identified in the Master's thesis [3], Madeleine felt that in time, "the curriculum user discovers "where the piece goes" (p. 62). She demonstrated an ongoing 
willingness to share and learn from others. For example, Madeleine consulted online teacher blogs, reviewed a plethora of FSL reading materials and improved her own French through extracurricular French training.

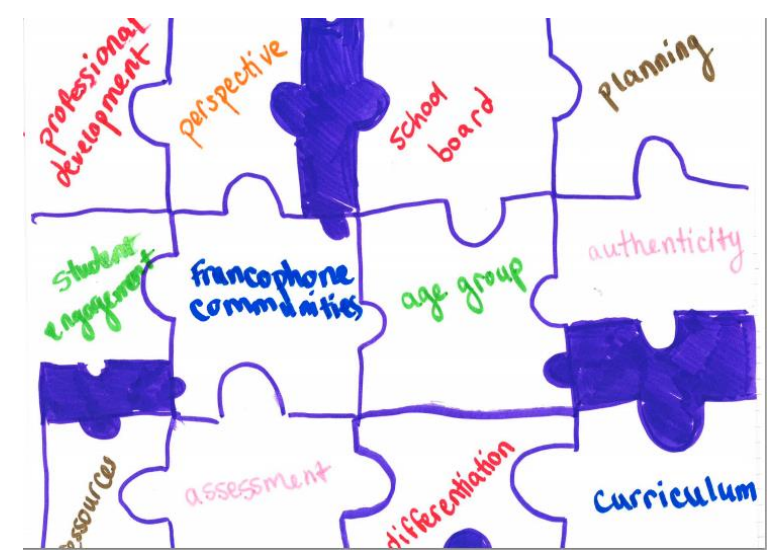

Figure 3. An almost complete curriculum puzzle

Helena, who received her Bachelor degree in French from the same university and at the same time as Madeleine, preferred the previous curriculum with its explicit grammar focus. Figure 4 is her representation of self in the middle of the 'road' as a new curriculum user.

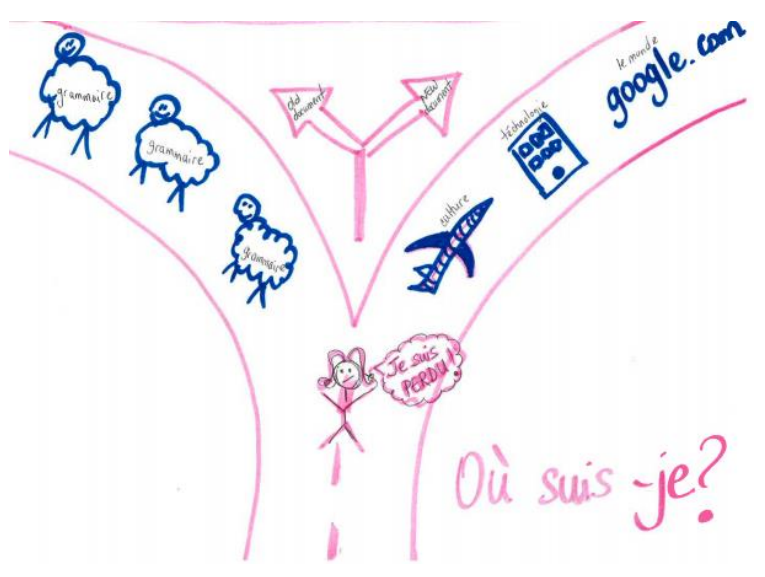

Figure 4. Helena at the crossroads

As evidenced in the study [3], Helena found curriculum and practitioner change as "a hard process" (p. 80). She felt that removing the explicit grammar expectations helped some students speak in French yet would not prepare the academically-bound students for university. As such, Helena drew herself as a sheep on the quest to follow the "leader [...] the blind leading the blind" (p. 80) at the 'crossroads' of deciding which unique path to follow as a new curriculum implementer.

Overall, the four teacher participants of this study appreciated the revised elementary curriculum's new intercultural strand and agreed that oral proficiency development was more important than written, grammatical accuracy. They implemented most of their curriculum strands by way of combining multiple expectations into one lesson. In fact, it was rare that participants taught one curriculum point per lesson. A significant finding identified was that all the participants asked for additional teacher training and funding for resources to successfully implement the revised elementary program.

The participant experiences and curriculum perceptions reflected Cummins' [16] nested pedagogical orientations. In this paradigm, teachers shift through different perceptions as to how to teach, each carrying different benefits and challenges. For example, the participants of the Master's thesis [3] transmitted explicit content such as grammar directly to their students with no authentic task to resolve. In other examples, the same teacher-participants shifted their practice to more of a socio-constructivist orientation by way of "hands on activities such as the restaurant and the wedding simulations, as well as having students fill out customs declaration cards" ( $p$. 102). The teachers also empowered their students through the transformative orientation when "selecting appropriate materials attainable and differentiated for each student" (p. 113). The orientations remind educators of the importance "to connect curriculum content to students' lives" (p. 31).

Their curriculum perceptions and operationalization techniques reflect the uniqueness and ontological stances of every Ontario FSL teacher regarding the ability and acceptance to adapt to curriculum change. Regardless of their teaching experience, their language proficiency, their district, and other factors, all four participants attempted to improve their practice with their own teacher-led change.

\section{Future Research Plans}

Scholars such as Cooke [12] have already identified that more Ontario FSL, and specifically CF teachers, are adapting to the new curriculum changes provided that additional learning time, ongoing professional development, and the provision of ample resources are provided. However, more time is required for FSL teachers implementing the new changes to truly determine curriculum success.

From personal experience teaching in an appliedlevel Grade 9 classroom during the period of September 2016 to January 2017, problems were still observed implementing the new secondary curriculum [2], specifically with regards to student incomprehension of authentic French. Personal attempts were made including a shift from grammatical accuracy to the ongoing teaching of authentic tasks in this beginner-level classroom. For example, diverse learning scenarios were implemented ranging from speed dating 
conversations, to 'ordering' pizzas in Montreal over the phone or online. Additionally, previously taught grammar points, such as the direct object pronouns in the past tense which dominated the previous curriculum edition, were not included.

Despite the removal of much of the explicit grammar teaching and the infusion of task-based opportunities in this classroom, many students were still dependent on online translation software to understand authentic French. Many could not form basic conversational sentences. The observed students still struggled speaking in spontaneous French while learning about French cultures.

This recent experience in the CF high school classroom suggests that additional curriculum training and research is required to successfully administer the curriculum and to further encourage student enrollment in FSL programs. CF teachers need to know the best way to engage with adolescent students using age-appropriate, yet level-appropriate language content for them to achieve the desired target language competencies.

To address some of the practitioner dilemma above, future doctoral-level research will build upon the Master's thesis [3] in the form of an exploratory case study that will contain classroom observations, questionnaires, teacher-researcher interviews and a culminating focus group.

Case study research as a methodology offers many affordances for investigating new content such as the Ontario FSL secondary curriculum [2]. Case study supporters such as Simons [17] have reminded researchers to clearly portray participants as they are "real people" (p. 15). This methodology-type builds knowledge, reflecting a personal epistemological stance to learn more about how to teach the intercultural sub-strand in all four curriculum areas. This 'exploratory' research inquiry recognizes that there is no hypothesis to prove for this specific research problem, but rather, an opportunity to capture unique, current and lived $\mathrm{CF}$ teacher experiences implementing curricular change. Additionally, exploratory case study research allows for greater insight regarding curriculum management techniques for other FSL stakeholders.

Moving away from the elementary context, this upcoming research will focus on the secondary teaching panel, specifically in the Grade $9 \mathrm{CF}$ classroom in the Greater Toronto Area. At present time, the following research question will guide the inquiry:

1. How do Ontario FSL high school teachers incorporate cultural knowledge in the beginner-level classroom?

- How do non-native French teacher-speakers live the curriculum's listening, reading, speaking and writing strands?

Inspired by the currere [4] programming standpoint, the inquiry will explore curriculum management that is dynamically interpreted by teacher to teacher in the Ontario CF context. This approach recognizes the uniqueness of each educator in the Ontario beginnerlevel, high school program that requires particular needs for true curriculum success as this learner is still beginning to acquire French-language and cultural skills.

\subsection{Participants and Recruitment Criteria}

6.1.1 Ontario CF Grade 9 Teachers. The teachers will need to be teaching at least one section of the Grade 9 CF program of either the applied or the academic stream from September 2018 to January 2019. Grade 9 is the selected area of research as it is the student's final year of mandatory French to obtain an Ontario high school diploma. Investigating the Grade 9 FSL teacher allows for a critical research environment where these educators are continuously seeking to motivate students in pursuing nonmandatory FSL classes post-Grade 9. Personal experience and that of fellow FSL colleagues dictate that Grade $9 \mathrm{CF}$ is the most prevalent course taught in the Ontario high school setting simply because it has the highest student enrollment. Previous statistics such as that from CASLT [13], have identified a tremendous drop of student attendance in higher grades of high school - in particular, for the CF context.

Approximately five to ten teachers will take part in the study to allow for rich participant 'portraits'. Ideally, to compare findings from the Master's thesis [3] to the doctoral work, the high school teachers will share the following characteristics:

- they will not be francophone-speaking teachers;

- $\quad$ they will be teaching in the Greater Toronto Area; and

- they will be both newly-licensed and experienced FSL high school teachers.

The non-native French teacher-speaker will be the focus of the future doctoral research because personal experience acknowledges the dominance of this teacher-type in the $\mathrm{CF}$ program more than the francophone teacher. Assumptions can be made that the non-native teacher may encounter greater difficulties in teaching the newly embedded intercultural curriculum component than the native counterpart. Additional research could help ignite participant exchange of curriculum resources and other professional development opportunities.

6.1.2 Ontario CF Grade 9 Students. The students will need to be non-native French-speaking learners pursuing either academic, applied, or open-level Grade 9 CF from September 2018 to January 2019. As Grade 9 is the final year for Ontario students to pursue 
FSL, the future exploratory case study can help determine student reactions with the current teaching of CF. Grade 9 is also the student's first experience in the high school setting. This potentially emotional time in the adolescent's life needs to be explored through research to specifically review how the student's identity discourse is developed in cultural disciplines such as French. Questions regarding their interest to continue with $\mathrm{CF}$ or even transition to $\mathrm{EF}$ or FI will be investigated. No other specific student recruitment criteria will be reinforced as to allow for full exploration of how the curriculum is perceived by a broad range of students.

\subsection{The Salade Niçoise: Conceptualizing the Ideal Core French Classroom}

The proposed research is inspired by theoretical notions of curriculum success in the second-language teaching context. The 'ingredients' for curriculum success derive from many theoretical perspectives that are added to a metaphorical salade niçoise, otherwise known as a French salad which is unique to the Nice region of France. While this illustrative framework focuses on the Ontario CF high school context, its overall structure can be used in other second-language teaching contexts.

The conceptual framework driving the future research inquiry, reflects a healthy Ontario FSL high school classroom as salad is generally conceived to be rich with beneficial ingredients for human consumption. This specific French food also supports the goal to teach French culture. As this salad contains a plethora of unique ingredients such as anchovies and eggs, it also represents the ongoing pursuit for the teaching of multiple French cultures. Salad, as a metaphor, also speaks to the uniqueness of each Ontario FSL high school curriculum user who will implement each strand differently in their localized context.

6.2.1. The Dynamic Salad Maker. The Ontario CF high school teacher is the creator of this salade niçoise, recognizing the uniqueness of each curriculum user. For example, a non-native French teacher formerly living in a francophone region for merely one year, may 'mix' the classroom salad differently than the native counterpart. Cummins' [16] work on the nested pedagogical orientations will help explain the uniqueness of each teacher's attitude to implementing the new curriculum and specifically, with regards to how culture and oral proficiency are developed in the $\mathrm{CF}$ high school beginner-level classroom. His framework can help determine if teachers are merely transmitting cultural content to students or transforming current culture, relative to the students' lived experiences. It is argued that the teacher predominantly has the curriculum 'control' as to what, and when, content is taught in his or her localized context.

6.2.2. The Necessary 'Protein'. When thinking of the salade niçoise, most individuals automatically consider the egg as the predominant ingredient. Egg as a protein, requires ongoing recycling of cultural content and oral-language opportunities for true student success in the beginner-level Ontario CF classroom. Netten and Germain's [15] neurolinguistic approach to second-language learning is the predominant 'egg' of this metaphorical framework as its characteristics model the ideal first-language acquisition development. According to their view, Netten and Germain [15] have argued that fluency in the target language begins with equal combinations of "implicit competence + explicit knowledge" (p. 90) that are often recycled throughout the semester and taught in a natural manner. The plethora of cultural characteristics needs to be appropriately accessible when the new learning environment supports the learner's pre-existing cultural and linguistic knowledge. For example, a French song on YouTube needs to include previously learned vocabulary along with new content so that the student transitions from merely learning to acquiring authentic content.

In another scenario using the neurolinguistic approach, student mistakes of verb tenses can be automatically corrected by the teacher who may restate the message with the correct verb tense in the same voice tone as an interlocutor, who in natural discourse, would not point out the verb tense mistake. Additionally, Netten and Germain [15] have identified that oral proficiency is obtained through student exposure to small 'chunks' of input for a subconscious retention. Students need to be given substantive 'practice-time' to use the language content with teacher guidance in lieu of ongoing, teacher-centered instruction. In time, through ongoing repetition, teacher-modeling, and time to practice the core vocabulary given to students, the learners automatically develop both proficiency and fluency.

6.2.3. The Intercultural 'Green Beans' and 'Tuna'. The string beans and tuna of a salade niçoise reflect a cultural 'sprinkling' in the second-language classroom. It is not the predominant ingredient as compared with the eggs as the beginner-level, secondlanguage classroom lacks language proficiency to truly engage in deep cultural interaction. To begin the scaffolding process for an improved learning experience, Jenkins and Purushotma [6] have provided teachers with a list of essential skills for participatory culture which include concepts such as "collaborative problem-solving" (xii), "play, performance, simulation, [and] collective intelligence" (xiv), and have acknowledged that cultural knowledge-learning is a continual "process" (p. 79). 
Essentially, culture-teaching needs to shift from the mere presentation of cultural artefacts, to mediating tools for interaction as argued by many theorists such as Swain, Kinnear and Steinman regarding the sociocultural theory [18]. Teachers need to plan their days thinking about how students will resolve authentic problems and interact in the target language as written grammar is no longer the dominant lesson focus.

6.2.4. The Intercultural 'Potatoes'. The teaching of culture and the exposure to multiple oral-language opportunities in the beginner-level second-language classroom often requires access to technology. Digital media can assist with identity reformation, sharing, regeneration and reconstruction as evidenced in previous research such as Thomas and Stornaiuolo [19].

Ong [20] has reminded stakeholders that orality exists in multiple forms. Specifically, we are in a period where the new orality is "secondary" (p. 11) in the form of "telephone, radio, television, and other electronic devices" (p. 11). Predominant orality focus now needs to be offered via social and digital media literacies as they are highly accessible to CF students and act as a vehicle for instantaneous communication. This virtual medium allows for transcultural opportunities in bridging the gap between the classroom and the culturally-rich, outside world.

6.2.5. The Salad 'Salt' and 'Pepper'. Curriculum cultural and oral fluency 'success' is not only influenced by the teacher's attitude but also by environmental affordances and or constraints. Inschool support such as principals, FSL-colleagues, and school colleagues, can influence the salad's overall 'taste' or otherwise known as the overall classroom learning experience which has been evidenced in Cooke's research study [12]. Personal experience has observed that Ontario FSL CF high school teachers often need to share technological equipment such as laptops with a large group of other colleagues. The consequence is that culturally-rich language opportunities are only offered to students in a 'signing out' process when these educators succeed in booking the required technology ahead of their peers. As a result, the educators who forget to rent the equipment often loose cultural-teaching opportunities as technology becomes the predominant medium to interculture.

In another scenario, funding for out-of-school cultural opportunities is often limited to a few hundred dollars to share with an entire French department, thus reducing what is embedded into the student's learning context.

Community assistance outside of the school can also influence the salad's overall 'flavor' or FSL learning experience such as the research in Cooke's [12] thesis. Parents who support the importance of
French may be better motivators to encourage student completion of cultural activities such as research assignments. As CF is the simplest language program offered in FSL, parental support can remind enrolled students that this type of French is still valuable for future language opportunities.

\section{Conclusion}

This article sought to present the dynamic nature of curriculum, culture, and interculture as concepts and their specific implications for the non-native Frenchteacher speaker working in beginner-level FSL contexts. Specifically, the research context of Ontario was selected for this inquiry as significant curriculum change has been initiated by the Ministry of Education. This article additionally sought to capture the lived experience of a teacher-researcher through previous work for a Master's-level thesis and upcoming doctoral-level thesis.

The ideal second-language classroom was initially conceptualized in the form of a metaphorical French salad; however, additional research is required to determine whether this specific classroom setting is applicable for the Ontario CF high school context.

Further questions extend to how additional Ontario FSL curriculum stakeholders such as curriculum consultants, prepare educators with the intercultural curriculum sub-strand and oral proficiency focus. As leaders to teachers, their perspectives and trainingtechniques can be important experiences to capture in future research.

Conceptions of culture, interculture, pluralistic views, French, and francophone definitions need to be further explored and conceptualized by all Ontario FSL stakeholders including its teachers, curriculum consultants, parents, and students. Their unique responses can outline their ontological stances and lived discourses that affect how the Ontario FSL curricula are experienced in the local community.

This is only the beginning of a necessary investigation into Ontario's revitalized elementary and secondary FSL curricula and specifically of the beginner-level, CF classroom.

\section{References}

[1] Ontario Ministry of Education, "The Ontario curriculum: French as a second language: Core, grades 4-8; Extended, grades 4-8; Immersion, grades 1-8, 2013", Queen's Printer for Ontario, [Internet], Toronto, Ontario, 2013, pp. 1- 320 .

[2] Ontario Ministry of Education, "The Ontario Curriculum, Grades 9 to 12: French as a Second Language - Core, Extended, and Immersion French, 2014 (revised)", Queen's Printer for Ontario, [Internet], Toronto, Ontario, 2014, pp. 1- 386. 
[3] R. Gour, "Engagement or despondence? Ontario middleschool core French teachers' perceptions of and experiences with the 2013 Ontario French as a second language curriculum", (Unpublished master's thesis). University of Toronto, Toronto, Ontario, 2015, pp. 1- 162.

[4] Pinnar, W. F., The character of curriculum studies: Bildung, Currere, and the recurring question of the subject, Palgrave Macmillan, New York, 2011.

[5] Elsen, A. and St. John, O. (2007). 'Learner autonomy and intercultural competence', in M. J. Raya and L. Sercu (Eds.), Challenges in teacher development: Learner autonomy and intercultural competence, (15-38), Peter Lang GmbH, Frankfurt.

[6] Jenkins, H. and R. Purushotma, Confronting the challenges of participatory culture: Media education for the 21st century, The MIT Press, Cambridge, MA, 2009.

[7] G. Furstenberg, "Making culture the core of the language class: Can it be done?", The Modern Language Journal, JSTOR, 2010, pp. 329-332.

[8] Byram, M., B. Gribkova, and H. Starkey, Développer la dimension interculturelle de l'enseignement des langues: Une introduction pratique à l'usage des enseignants. Conseil de l'Europe, Strasbourg, 2002.

[9] Skutnabb-Kangas, T., and McCarty, T. L. (2008). 'Key concepts in bilingual education: Ideological, historical, epistemological, and empirical foundations', in J. Cummins, N. Hornberger (Eds.), Bilingual Education, Volume 5, 2nd edition. New York: Springer, pp. 3-17

[10] Witte, A, Blending spaces: Mediating and assessing intercultural competence in the L2 classroom, De Gruyter Mouton, Boston, 2014.

[11] J. Cummins," "To what extent are Canadian second language policies evidence-based? Reflections on the intersections of research and policy", Frontiers in Psychology, [Internet], Canada, May 2014, pp. 1-10.

[12] S. Cooke, "The self-efficacy beliefs of novice elementary French as a second language teachers", (Unpublished master's thesis), University of Western Ontario, London, Ontario, 2013, pp. 1- 119.

[13] Canadian Association of Second Language Teachers (CASLT). "Improving French second language education through effective partnerships", CASLT, Ottawa, Ontario, 2006.

[14] House of Commons, "The state of French secondlanguage education programs in Canada: Report of the standing committee on official languages", 41st Parliament, Second Session, House of Commons, [Internet], Ottawa, Ontario, February 2014.

[15] J. Netten and C. Germain, "A new paradigm for the learning of a second or foreign language: The neurolinguistics approach", Neuroeducation, Canada, December, 2012, pp. 85-114.
[16] Cummins, J., K. Brown, and D. Sayers. Literacy, Technology and Diversity: Teaching for Success in Changing Times, Pearson Education, Boston, Massachusetts, 2007.

[17] Simons, H, Case study research in practice, Sage Publications, Ltd., London, UK., 2009.

[18] Swain, M., P. Kinnear, and L. Steinman, Sociocultural theory in second language education. An introduction through narratives. (2nd ed.), Multilingual Matters, New York, 2015.

[19] E. E. Thomas, and A. Stornaiuolo, "Restorying the self: Bending toward textual justice", Harvard Educational Review, Boston, MA., 2016, pp. 313-338.

[20] Ong, W. J., Orality and literacy: The technologizing of the world, Routledge, Cornwall, UK, 1982 